\title{
CONTRIBUIÇÃO HISTÓRICA DA ENFERMAGEM NA FORMAÇÃO DO CONCEITO PROCESSO SAÚDE-DOENÇA-CUIDADO
}

\author{
Carlos Roberto FERNANDES*
}

*Enfermeiro, Mestre em Enfermagem, Doutorando em Enfermagem, Professor Assistente na Universidade Federal do Espírito Santo, Departamento de Ciências da Saúde do Centro Universitário Norte do Espírito Santo, São Mateus-ES. E-mail: crfernandes-enf1@ @otmail.com

Recebido em: 15/05/2013 - Aprovado em: 30/07/2013 - Disponibilizado em: 15/08/2013

\section{Resumo}

A utilização do sintagma processo saúde-doença-cuidado surge escrita de várias formas, sem explicitação sistemática de sua significação ou sem clareza conceitual, dificultando discussão sobre o conceito. Com matriz semântica comum, mesmo admitindo-se sua polissemia, é possível dar um passo para a efetivação de pesquisa sobre formação e desenvolvimento daquele conceito. Objetivo: propor a formação sistemática do conceito processo saúde-doençacuidado a partir de uma Teoria Geral do Cuidado. Metodologia: Pesquisa teórica, não experimental, documental, com abordagem histórica. O método é histórico e heurístico, à luz do Historismo de Wilhelm Dilthey. A técnica é historista em seus fundamentos para a formação científica de conceitos. Resultados e Conclusão: O marco histórico de publicações brasileiras nas quais se utiliza o sintagma processo-saúde-doença-cuidado (sem alteração dessa grafia) é em 2000, sinomizando-o ao conceito de processo saúde-doença. Na Enfermagem, diferenciando-o do conceito processo saúde-doença, a primeira sistematização do conceito processo saúde-doença-cuidado se dá em 2010, desenvolvido a partir de uma Teoria Geral do Cuidado e da contribuição histórica das pesquisas de Enfermagem sobre Cuidado e Processo de Cuidado.

Palavras-Chave: Enfermagem. História da Enfermagem. Processo Saúde-Doença-Cuidado.

\section{HISTORIC CONTRIBUTION OF NURSING IN CONCEPT FORMATION HEALTH -DISEASE-CARE PROCESS}

\section{Abstract}

The use of the sintagm health-disease-care process arises variously written without systematic explanation of its meaning or without conceptual clarity, so that the discussion of the concept. Headquartered common semantics, even assuming its polysemy, you can take a step towards the realization of the research on the formation and development of this concept. Objective: to propose the concept of systematic training in health-disease-care of a general theory of attention. Methodology: The research is theoretical, not experimental, with historical approach. The heuristic method is historical and, in light of the Historism of Wilhelm Dilthey. The technique is historista on their land for the formation of scientific concepts. Results and conclusions: The benchmark brazilian publications in which he uses the term healthdisease-care (no change this spelling) is in 2000, identical to the concept of the process health-disease. In nursing, the first systematization of the concept of health-disease-care takes place in 2010, differentiated the process health-disease itself and developed from a general theory of Care and the historical contribution of research nursing Care and what the care process.

Keywords: Nursing. History of Nursing. Health-Disease-Care Process. 


\section{CONTRIBUCIÓN HISTÓRICA DE LA ENFERMERÍA EN LA FORMACIÓN DEL CONCEPTO PROCESO SALUD-ENFERMEDAD-CUIDADO}

\section{Resumen}

El uso de la frase la salud-enfermedad-cuidado surge escrito de diversas maneras, sin explicación sistemática de su significado o sin claridad conceptual, por lo que la discusión del concepto. Con sede semántica común, incluso asumiendo su polisemia, se puede dar un paso hacia la realización de la investigación en la formación y desarrollo de ese concepto. Objetivo: proponer el concepto de proceso sistemático de capacitación en salud-enfermedad-cuidado de una Teoría General de lo Cuidado. Metodología: La investigación es teórica, no experimental, con enfoque histórico. El método es histórico y heurístico, a la luz del Historismo de Wilhelm Dilthey. La técnica es historista en sus terrenos para la formación científica de conceptos. Resultados y conclusiones: El punto de referencia de las publicaciones brasileñas en las que él usa el término proceso salud-enfermedad-cuidado (no cambiar esta ortografía) es en 2000, sinomizando al concepto de proceso salud-enfermedad. En la Enfermería, la primera sistematización del concepto de salud-enfermedad-cuidado se lleva a cabo en el año 2010, diferenciado del proceso salud-enfermedad en sí y desarrollado a partir de una Teoría General del Cuidado y la contribución histórica de las investigaciones de Enfermería sobre lo Cuidado y el Proceso de Cuidado.

Palabras-Clave: Enfermería. Historia de la Enfermería. Proceso Salud-Enfermedad-Cuidado.

\section{Introdução}

Amplamente utilizada em História, Teoria Política e Filosofia Política, a História dos Conceitos (também chamada de História Conceitual) não se circunscreve às fronteiras disciplinares das Ciências Políticas e Ciências Sociais - aliás duas constelações do universo das Ciências do Espírito (Geisteswissenschaften, assim denominadas por Wilhelm Guillermo Dilthey, no final do século XIX.

\section{A "nova" História dos Conceitos é} campo epistêmico iniciado na Alemanha e por historiadores alemães nos anos das décadas de 1950 e 1960: o maior expoente contemporâneo da História dos Conceitos (Begriffsgeschichte) é Reinhart Koselleck (1923-2006). E "nova” (entre aspas) porque a Begriffsgeschichte advém da secular tradição germânica de Filologia, de História da Filosofia e da Hermenêutica - uma tradição perante a qual Dilthey afirma: toda ciência e toda filosofia são ciências empíricas, ou seja, nascem da Vivência (Erlebnis) e não por uma metafísica vontade de saber; "toda ciência é ciência da experiência" (e não do experimento). (DILTHEY, 1986, p.33, 39)

A afirmação de Dilthey de que a Vivência é a relação humana primária e fundante e o Conhecimento (uma expressão da vivência) é a relação humana secundária e daquela derivada corresponde ao fundamento da consciência científico-espiritual (ou experiencial): todo conceito correlaciona-se à experiência e é por esse mar da empiria em seu tecido emaranhado de história que nenhum conceito pode estar desagregado da vivência (de onde procede); é também pela consciência histórica desse nexo conceito- 
vivência em suas regularidades e conexões que nasce todas as formas de poder sobre a vida sociopolítica. (DILTHEY, 1907; DILTHEY, 2003, p.72-3)

Estendendo a afirmação de Dilthey sobre Vivência e Conhecimento à História dos Conceitos, estes são sempre históricos e humanos porque são produzidos por pessoas (e não por entes metafísicos e não humanos) que vivem um momento histórico não iniciado ontem; portanto, a História dos Conceitos é uma historiografia da formação (bildung) de conceitos. (As palavras alemãs bilden [formar] e bildung [formação] tem significações estritas. Bilden é "atividade produtora do aperfeiçoamento de todos os processos de uma alma", ou seja, de um indivíduo, um povo; e Bildung, o equivalente germânico para o conceito de cultura, é "todo gênero daquele aperfeiçoamento da alma", (DILTHEY, 1949, p.52) ou seja, de uma língua, de uma arte, de uma ciência, de uma filosofia, de uma ideia... O esclarecimento é registrado por Dilthey entre 1884 e 1894, na Universidade de Berlim). A tradição do conceito alemão e histórico de formação, conforme lembra Hans-Georg Gadamer, é o conceito fundante das Ciências do Espírito mais fundamental e central que o conceito de método para as Ciências Experimentais. (GADAMER, 1999, p.59)

No aproveitamento das considerações acima, ao se abordar a emergência do sintagma e do conceito processo saúde- doença-cuidado pensa-se naquela historiografia da formação de um conceito, impossível de ser realizada nos limites de um artigo. Apesar desse limite, constata-se, a partir de 1992, em eventuais publicações de Enfermagem e de outras áreas da Saúde, o advento de sintagmas diferentes (pelo menos na formação dos termos que os constituem) do conceito processo saúde-doença: processo de ser saudável/adoecer/curar, processo de viver/ser saudável/adoecer e curar, processo saúde/enfermidade/atenção, processo saúdeenfermidade-cuidado, processo saúdeadoecimento-cuidado, processos saúde/enfermidade/cuidados, processo saúdedoença-cuidar, processo de saúde-doençacuidado, processo saúde-doença-cuidado.

Os novos sintagmas são registrados de diferentes formas quase ao mesmo tempo em que outros pesquisadores de Enfermagem afirmam, pelo menos quatro posições diferentes (ou divergentes?) com relação aos sintagmas processo saúde-doença, processo saúdeldoença e processo saúde-doençacuidado.

- em 1997 defende-se o fundamento transdimensional do cuidado, diante do qual o processo saúde-doença é função-meio e não a função-fim:

o processo saúde-doença é somente uma pequena dimensão da vida. $\mathrm{O}$ processo saúde-doença não pode ser considerado um fim em si mesmo, como vem sendo habitualmente tratado na enfermagem, mas como meio para que possamos atingir novos níveis de expressão da consciência. (SILVA, 1997, p.37) 
- o processo saúde-doença torna-se uma espécie de "chave-mestra" em alguns discursos nas Ciências da Saúde a ponto de tornar-se um fim em si mesmo. Em 2000, declara-se: os "processos saúde/doença da população, quer na face individual, quer na face coletiva," são o objeto de trabalho da Enfermagem. (EGRY, SENA, 2000, p.20)

- no mesmo ano de 2000, afirma-se ser o processo saúde-doença-cuidado o objeto de trabalho (ou um dos complexos objetos) das Ciências da Saúde. (ROCHA, ALMEIDA, 2000)

- em 2007, declara-se ser o processo saúdedoença-cuidado o objeto de estudo da Saúde. (PINHO, SANTOS, 2007)

Pela emergência e uso de vários sintagmas nas publicações de Enfermagem e de outras Ciências da Saúde, e de concepções aparentemente díspares, surge a indagação óbvia: há diferença ou sinonimização entre as diferentes variações semânticas do sintagma processo-saúde-doença-cuidado?

O uso de uma expressão escrita de várias formas diferentes, sem explicitação sistemática dos seus significados ou sem clareza se se trata de um mesmo conceito ou de conceitos diferentes dificulta (ou até impede) qualquer discussão científica com base epistemológica: com uma matriz semântica comum, mesmo admitindo-se sua polissemia, é possível dar um primeiro passo para a efetivação de pesquisa sobre formação e desenvolvimento de um determinado conceito: pretende-se contribuir para esta possibilidade, propondo-se uma matriz semântica descritiva do sintagma processo saúde-doença-cuidado.

\section{Objetivo}

- formar o conceito processo saúde-doençacuidado a partir de uma Teoria Geral do Cuidado, destacando-se o marco histórico de publicações na área da Saúde utilizadoras do sintagma ou variações semânticas do mesmo.

\section{Material}

O material bibliográfico não constitui revisão de literatura e é estritamente utilizado para determinação do marco histórico quanto ao uso do sintagma (incluindo suas variações semânticas e outras formulações conceituais) em publicações científicas.

\section{Metodologia}

A pesquisa é teórica (quanto ao gênero), não experimental (quanto ao tipo), histórica (quanto a abordagem). O método é histórico e heurístico, estritamente à luz do Historismo de Dilthey.

A técnica de pesquisa é denominada historista, elaborada por Fernandes (2007), em seus fundamentos para a formação científica de conceitos, assim esquematizada a partir de duas fontes:

- primeira, as etapas para a construção científica de um conceito, utilizadas na pesquisa historista de Dilthey com o objetivo de investigar "a lei de formação que rege a 
gênese de cada sistema filosófico particular;" (DILTHEY, 2003, p.69)

- segunda, as etapas básicas utilizadas por Gadamer (1999) no estudo do conceito de vivência (Erlebnis).

As etapas da técnica historista para a formação científica de conceitos são:

-esclarecer a origem ou a história da palavra escolhida ou criada. Essa escolha não se restringe à etimologia mas às vivências formadoras da própria etimologia.

-determinar a origem ou a história do conceito escolhido ou criado;

-escolher ou identificar que fatos da realidade histórico-social-humana serão traduzíveis do nome ou da expressão geral;

-discriminar os diversos tipos de experiências, gerados pelas vivências e concepções de pessoas e comunidades de pessoas, traduzíveis do que possa traduzir o conceito criado. Tais vivências e concepções são denominadas de abreviaturas do fato;

-separar as abreviaturas distorcivas, falsas ou insuficientes do fato que, porventura, tenham sido ou possam ser anexadas ao nome ou expressão geral criada ou escolhida; tais abreviaturas são tidas por relações isoladas ou arbitrárias entre vivências de fato - realidades de fato - abreviaturas de fato;

-compor traços distintivos, traços essenciais e traços suficientes dos fatos, expressivos do conceito criado ou escolhido. Essa composição permite a definição do conceito, onde objeto epistemológico, objeto de trabalho, fundamentos teóricos, metodológicos, epistemológicos, históricos, filosóficos, técnico-instrumentais e campo de ação estarão delimitados. Eis o diagrama elaborado para essa constituição científica de um conceito, de acordo com as diretrizes metodológicas de Wilhelm Dilthey para a sua investigação do conceito de filosofia: (FERNANDES, 2007, p.15)

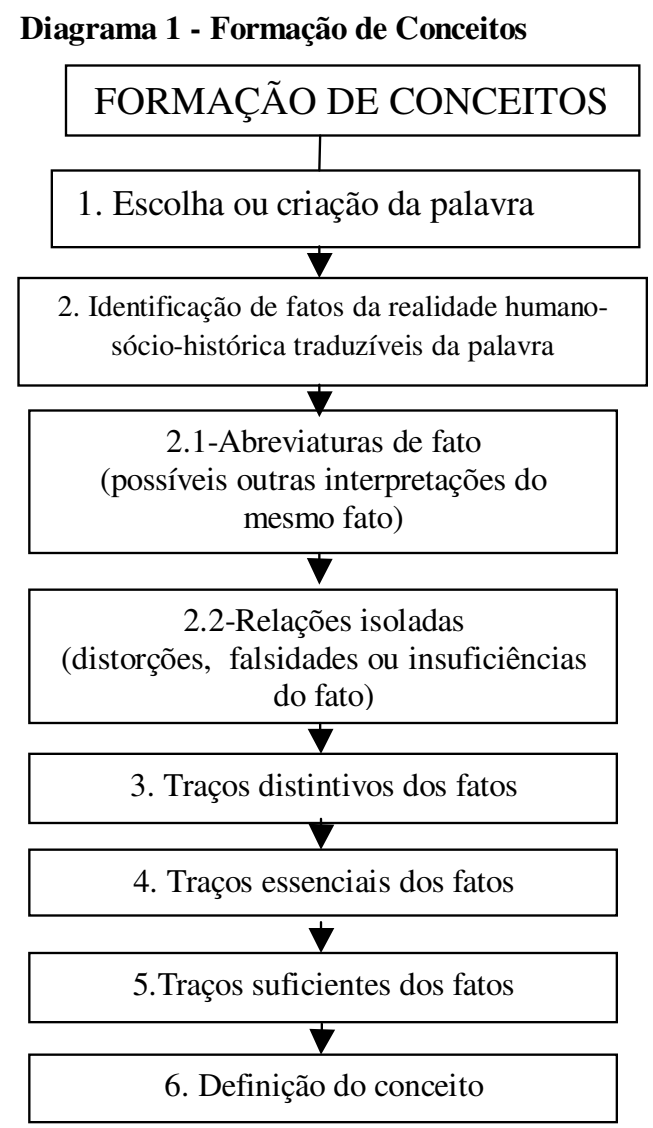

Fonte: o autor

\section{Material}

Exclusivamente para atender ao item 2 do diagrama para formação científica de conceitos e não para constituir referencial teórico ou conceitual, utilizou-se como descritor o sintagma processo saúde-doençacuidado para busca das fontes bibliográficas em sistema informatizado ou impresso e sem 
corte temporal. A busca documental foi realizada: em periódicos latinoamericanos, impressos ou informatizados; em livros de Enfermagem, escritos nas línguas portuguesa ou espanhola, nos quais apareceram o sintagma processo saúde-doença-cuidado; em livros de outras áreas da Saúde; em Anais de Congressos, Simpósios, Seminários e Colóquios de Enfermagem.

As bases de dados investigadas para periódicos e sem corte temporal foram: Scielo Brasil (Scientific Electronic Library Online), Scielo Argentina (Salud Colectiva) BDENF (Banco de Dados de Enfermagem), Lilacs (Literatura Latinoamericana de Ciências da Saúde) e PubMed (Publicações Médicas).

O critério de inclusão: conter no título, no resumo ou no corpo do trabalho o sintagma processo saúde-doença-cuidado ou (aparentemente) o mesmo sintagma com variações semânticas na constituição do mesmo.

O critério de exclusão: a) monografias, dissertações e teses não publicadas em livro; b) trabalhos impressos ou informatizados em línguas diferentes da portuguesa e espanhola; c) trabalhos replicados em alguma das cinco bases (Scielo Brasil, BDENF, Lilacs, Scielo Argentina - Salud Coletiva, Pubmed) foram automaticamente excluídos de uma delas; d) livros e artigos fora da área da Saúde; e) trabalhos em suporte impresso ou em base online que apresentem no título e no corpo de texto exclusivamente os sintagmas processo saúde-doença, processo de saúde, processo de doença (e possíveis variações semânticas em algum dos termos constituidores do sintagma).

Utilizando-se a matriz semântica processo saúde-doença-cuidado (process health-disease-care, health-disease-care, utilizados em PubMed) foram encontrados: 7 (sete) artigos na Scielo Brasil, 5 (cinco) artigos no BDENF, 15 (quinze) trabalhos na Lilacs, 18 (dezoito) artigos em PubMed, 6 (seis) trabalhos no Scielo Argentina (Salud Coletiva). Além destes e possuindo o pesquisador em suporte impresso a Revista Texto Contexto Enfermagem (de 1992 a 2007), tal revista foi particular e manualmente consultada, tendo-se considerado para análise, independente do descritor, o volume 1, número 2, de julho a dezembro de 1992, com 15 (quinze) artigos publicados, e o volume 2, número 1, de janeiro a junho de 1993, com 9 (nove) artigos publicados, excluindo-se as Notas Prévias e os Resumos de Dissertação. Dos 24 (vinte e quatro), após lidos, foram selecionados 3 (três) artigos em que apareceram o termo processo interligado a outros termos ou mais relativos ou variáveis aos conceitos de saúde e doença.

Do total dos 51 artigos encontrados nas cinco bases de dados referidas, após lidos integralmente, foram descartados os que não continham em seu resumo ou conteúdo o descritor processo saúde-doença-cuidado; a 
esse descarte acrescentaram-se as publicações duplicadas e as teses (encontradas na Lilacs).

Quanto aos livros foi encontrada exclusivamente uma publicação com o descritor processo saúde-doença-cuidado em seu título e em todo o seu conteúdo, tendo-se considerado uma segunda publicação para estudo extrapolador do conceito de processo saúde-doença; cinco publicações foram encontradas trazendo em alguma parte do seu conteúdo aquele descritor ou variações semânticas na constituição do sintagma de referência.

Por não se constituir em objetivo da pesquisa a realização de análise temática, análise de discurso, análise de conteúdo ou análise ideológica, os trabalhos foram analisados quanto a presença do sintagma processo saúde-doença-cuidado, a explicitação ou a definição do sintagma utilizado (ou eventual sistematização do conceito), a sua diferenciação ou sinonimização ao conceito de processo saúdedoença: variações semânticas na constituição do sintagma foram identificadas (e não descartadas).

\section{Resultados e discussão}

Quanto ao uso da matriz semântica processo saúde-doença-cuidado (considerando as variações semânticas na formação do sintagma e o uso de outros sintagmas) compilou-se um total de 24 artigos (Quadro 1), 6 trabalhos em capítulos de livros (Quadro 2), 2 livros (Quadro 3) e 1 trabalho de pesquisa constante em Anais de Seminário (Quadro 4), publicados entre 1992 e 2011 e somando-se 33 pesquisas estudadas.

De acordo com o diagrama 1 elaborado para a formação científica de conceitos:

\section{Escolha ou criação da palavra (Item}

1 do diagrama 1)

O sintagma escolhido (matriz semântica) é processo saúde-doença-cuidado, sem quaisquer variações semânticas das palavras por ele constituídas, incluindo o hífen entre os termos saúde-doença-cuidado: a história do sintagma procede das concepções e de suas mudanças sobre saúde, doença, cuidado, desde a declaração da Organização Mundial de Saúde, em 1946, de que saúde não é mera ausência de doença e a partir da Primeira Conferência Internacional sobre Promoção da Saúde, realizada em novembro de 1986, além da Teoria Geral do Cuidado proposta em 2007 e da revisão dos métodos de processo de cuidado. (FERNANDES, 2007)

Identificação de fatos da realidade humano-sócio-histórica traduzíveis da palavra (Item 2 do diagrama 1)

$$
\begin{aligned}
& \text { Apesar das multidiversas e } \\
& \text { pluridiferenças concepções teóricas e } \\
& \text { metodológicas, das separações e intersecções } \\
& \text { entre campos epistêmicos, encontram-se } \\
& \text { totalmente ou parcialmente (em todos os } \\
& \text { trabalhos publicados) alguns traços essenciais }
\end{aligned}
$$


do fato (= processo saúde-doença-cuidado), apontados no item 4 do diagrama.

Abreviaturas de fato (subitem 2.1 do diagrama 1)

Definidas por Dilthey (2003) como as possíveis outras interpretações do mesmo fato, todos os sintagmas diferentes de processo saúde-doença-cuidado (e aqueles escritos de forma diferente dessa estabelecida) foram considerados abreviaturas de fato: processo da morte e do morrer; (SILVA, BORENSTEIN, 1992) processo de ser saudável/adoecer/curar; (LEOPARDI, 1992) processo de viver/ser saudável/adoecer e curar; (LEOPARDI, 1993) processo de ser e viver saudável; (SILVA, 1997) processo saúde/enfermidade/atenção; (MENÉNDEZ, 1998) processo saúde-doença e cuidado; (ALMEIDA et al, 1999) processo saúdeenfermidade-cuidado; (BUSS, 2003) processo de saúde-doença e sofrimento; (LACERDA, VALLA, 2004) processo de ser saudáveladoecer-curar-se; (CECCIM, 2004) processos saúde/enfermidade/cuidados; (GARNELO, LANGDON, 2005) processo saúde-doençacuidar; (GOMES, SCHRAIBER, COUTO, 2005) processos de saúde/enfermidade/atenção; (CANTO, 2006; MENÉNDEZ, 2008) processo saúdeenfermidade-atenção;

(SACCHI, HAUSBERGER， PEREYRA， 2007; MAZZEO, 2007) processo saúdepadecimento-enfermidade-atenção;

(MORENO, 2007) processo de saúde-doença- cuidado, processos de saúde/doença/cuidado; (MORAES, GOMES, 2007) processos de saúde-doença-atenção; (DIEHL， GRASSI, 2010) processo sofrimento-adoecimentocuidado. (BRANT, GOMES, 2007)

Relações isoladas (subitem 2.2 do diagrama 1)

Definidas por Dilthey (2003) como distorções ou falsidades do fato, todas as pesquisas que se utilizaram do sintagma processo saúde-doença-cuidado e o sinonimizaram a processo saúde-doença foram considerados relações isoladas (embora não necessariamente distorcivas ou falsas do fato). (ALMEIDA et al, 1999; REIS, XAVIER，2003; (ROSA，CAVICCHIOLI, BRÊTAS, 2006; ALVES, NUNES, 2006; MACHADO, CAR, 2006; MORAES, GÓMES, 2007; TOLEDO, RODRIGUES, CHIESA, 2007; DITTERICH, CABARDO, MOYSÉS, 2009; BEZERRA, SILVA, 2010; DEMÉTRIO et al, 2011)

Traços distintivos do fato (item 3 do diagrama 1)

Num primeiro momento, foram considerados todos os trabalhos utilizadores do sintagma processo saúde-doença-cuidado (sem alteração dessa grafia), mesmo que na maioria deles não tenha sido possível identificar a concepção dos articulistas sobre o sintagma; (ROSA, ALMEIDA, 2000; ROSA, CAVICCHIOLI, BRÊTAS, 2005; LOPES et al, 2005; PINHO, SANTOS, 2007; FERNANDES, $\quad$ SOUZA, 2009; 
FERNANDES, 2010) no segundo momento, foram considerados os trabalhos que, em parte ou no todo, apresentaram traços comuns (características típicas de diferenciação do conceito): estes traços típicos passaram a ser considerados traços essenciais do fato, sobretudo por sua recorrência em diversos trabalhos, por diferentes autores, em diversificadas fontes divulgadoras, de diferentes campos epistêmicos e até de nacionalidades diferentes.

Traços essenciais do fato (item 4 do diagrama 1)

Foram considerados traços essenciais do fato:

-não sinonimização a processo saúde-doença; -não biologicismo (incluindo não sociologismo, não antropologicismo), não medicocêntrico, não tecnocêntrico;

-as tradições de pesquisas pluri-intertransdisciplinares sobre as multidiversas dimensões e expressões sociais e étnicas do processo de cuidado, sobretudo (e não exclusivamente) no Brasil e nos demais países latinoamericanos; nesse sentido, destacam-se as proposições de teóricos da Enfermagem, incluindo o pensamento e o trabalho de Florence Nightingale, desde que aquelas proposições não estivessem limitadas ao cenário hospitalar e nem sinonimizando processo de cuidado com técnicas e procedimentos de Enfermagem.
Independente das multidiversas e pluridiferenças entre as concepções de saúde, de doença, de enfermidade, de sofrimento, de padecimento e das eficiências e ineficiências das atenções (profissionais ou estatais), constituem traços essenciais do fato (processo saúde-doença-cuidado) a concepção de ser um conceito histórico, adstraído das vivências e experiências individuocoletivas de cuidado (e de não cuidado) com o corpo e com os ambientes, espaços e contextos da vida humana, incluindo todos os demais ecossistemas vivos; por ser histórico possui indissociáveis as dimensões biológicas, psicológicas, sociais, antropológicas (culturais, étnicas-pluriétnicas-interétnicas, de gênero, políticas, econômicas, linguísticas...), organizacionais (tanto com relação aos sistemas de organização interna quanto externa das sociedades), epistêmicas (ou seja, os sistemas culturais, tais como ciências, filosofias, religiões, artes..., incluindo obviamente arquitetura, engenharia, ecologia). Tais características são típicas, ou seja, são o traço comum (a essência, a natureza, o cerne, o motivo) a ser identificado, independente do momento histórico e independente daquelas multidiversa e pluridiferenças disciplinares entre as concepções de saúde, de doença, de enfermidade, de padecimento, de sofrimento, de ser e estar saudável: não havendo tais características típicas não serão identificados ou percebidos os nexos (históricos, vivenciais e efetivos) para a formulação do conceito geral de processo saúde-doença-cuidado. 
Todas aquelas dimensões expressam nexos efetivos, estrutural e vivencialmente existentes (não por teorias, por métodos, por vontade ou por alguma concepção de razão=racionalismo que não seja histórica, como efetivamente o é).

Todos os traços essenciais do fato (processo saúde-doença-cuidado) resumem-se num só: histórico.

Por dificuldade de compreensão de que tudo o que é humano é histórico, discriminam-se as características (ou as dimensões interconexas) do processo saúdedoença-cuidado, destacadas-comentadas ou às vezes apenas citadas, pelos diferentes autores: filosófica, epistemológica, metodológica, criativa, afetiva, estética, ética, terapêutica, social, étnica, intercomunitária, espiritual, gerencial ou organizacional, biológica, sensível, intuitiva, moral, interpessoal, política, fisiológica, pedagógica, expressiva, de Gênero, ontológica, educacional, psicossocial, cultural, interdisciplinar, transdisciplinar, econômica, cosmológica, tecnológica.

O trabalho de Fernandes (2010) reuniu todas estas características (ou dimensões) do processo de cuidado, interpretando-as como extensíveis ao processo saúde-doençacuidado.

Traços suficientes do fato (item 5 do diagrama 1)

Foram considerados traços suficientes do processo saúde-doença-cuidado a sua não sinonimização a processo saúde-doença com explicitação da(s) concepção (ões) do processo saúde-doença-cuidado, a possível procedência da formulação de bases teóricas e metodológicas explicitadoras do processo de cuidado (não reduzido a técnicas e procedimentos centrados num profissional ou em vários profissionais), a possível formulação de uma Teoria Geral do Cuidado da qual derivam necessariamente novas lógicas, novas concepções (e, eventualmente, novos conceitos) de saúde, doença.

Mais claramente, destacam-se na apresentação e na explicitação sistemática de traços suficientes do processo saúde-doençacuidado: Silva (1997), embora não se utilize desse sintagma, propõe a extrapolação do processo saúde-doença visto como meio e não em si mesmo, além de elaborar a Teoria Transdimensional do Cuidado; e Fernandes (2010), sobretudo propondo fundamentos do processo saúde-doença-cuidado derivados da tradição de pesquisas de Enfermagem no âmbito do processo de cuidado, além de elaborar a Teoria Geral do Cuidado com uma formulação transdisciplinar e revisar as propostas metodológicas das teóricas de Enfermagem concebendo-as como métodos do processo de cuidado. (FERNANDES, 2007; FERNANDES, 2010)

\section{Definição do conceito}

O único trabalho publicado apresentador de uma definição do processo saúde-doença-cuidado (PSDC) é o de 
Fernandes para o qual a formação desse conceito emerge

da tradição de saberes e de prática de cuidado no campo da Enfermagem e cuja expressão máxima é o trabalho de Florence Nightingale, traduz a inseparabilidade dos ambientes natural, psíquico, psicológico, físico ou material em que pessoas e coletividades historiografam em seus corpos e na sociedade em que vivem os seus processos de cuidado, de não cuidado e de autocuidado. (FERNANDES, 2010, p.4)

PSDC “ não é um nôumeno nem um fenômeno.” É

um desenvolvimento (=diferenciação e aperfeiçoamento) do processo saúde-doença a partir da particular contribuição práxica das Ciências da Enfermagem sobre o processo de cuidado; portanto, não é uma evolução do conceito de processo saúde-doença nem uma mera adição ou inclusão do cuidado nesse processo. (FERNANDES, 2010, p.45)

Algumas dimensões do processo de cuidado e, consequentemente, do PSDC:

criativa, terapêutica, afetiva, estética, ética, expressiva, sensível, intuitiva, política, metodológica, histórica, pedagógica, epistemológica, filosófica, interpessoal, fisiológica, intercomunitária, espiritual, gerencial ou organizacional, tecnológica, de Gênero, socioeconômica, étnica, moral. (FERNANDES, 2010, p.18-9)

No "PSDC, o que as pessoas e as coletividades humanas fazem é consequente ao que pensam, em um dado momento histórico e segundo determinadas formas de suas organizações sociais.” (FERNANDES, 357)

\section{Conclusão}

O marco histórico de publicações científicas brasileiras de Enfermagem nas quais se utiliza o sintagma processo-saúdedoença-cuidado (sem alteração dessa grafia) é o ano de 2000, sinomizando-o ou interpolando-o com o conceito de processo saúde-doença. (ROCHA, ALMEIDA, 2000)

$\mathrm{Na}$ Enfermagem, a primeira sistematização do conceito processo saúdedoença-cuidado se dá exclusivamente em 2009 e em 2010. (FERNANDES, SOUZA, 2009; FERNANDES, 2010) Com esta sistematização, torna-se possível a discutibilidade dentro da própria área de Enfermagem e com as várias outras áreas do conhecimento sobre o conceito de processo saúde-doença-cuidado (sem variabilidade dos termos constituidores do sintagma), promovendo, dessa forma, um possível avanço na Enfermagem quanto as bases epistemológicas do referido conceito.

Na sua concepção histórica e historista (não historicista) de mundo, Fernandes e Souza (2009) e Fernandes (2010) apresentam o conceito de processo saúde-doença-cuidado como desenvolvimento, ou seja, diferenciação do próprio processo saúde-doença e aperfeiçoamento do Cuidado de Enfermagem e do Processo de Cuidado: este desenvolvimento se deu e está se formando nas próprias trajetórias e memórias dos 
profissionais - notadamente de enfermeiros e enfermeiras, com fatos gerados em suas vidas, em seus estudos e no trabalho de Enfermagem - em todas as suas dimensões (de ensino, gerenciais, assistenciais, de pesquisa). $\mathrm{O}$ autor, vinculado ao mundo da Enfermagem, coloca teoricamente estas questões em termos conceituais de trajetórias e memórias de corpo dos enfermeiros e das enfermeiras; tais trajetórias e memórias de corpo são vivenciadas no mar empírico da história e no tecido emaranhado de história (do próprio trabalho de Enfermagem e dos saberes dele decorrentes sem, na maioria das vezes, serem formatados e traduzidos em linguagem acadêmica): aquelas trajetórias são a própria história (do Corpo e do Cuidado) e aquelas memórias são a própria historiografia (do Corpo e do Cuidado de Enfermagem) indissociáveis de todas as unidades de cuidado (indivíduos, famílias, grupos, comunidades, ambientes, animais e os próprios profissionais de Enfermagem de todos os graus acadêmicos).

No conjunto da obra de Fernandes (2010), percebe-se a nítida intenção do autor em explicitar a contribuição ímpar da Enfermagem, preconizando uma Nova
Enfermagem como Ciência do Cuidado, para as demais Ciências da Saúde, Ciências Humanas e Ciências Sociais; e, para isto, em busca de uma unidade e unificação explanatória de variadas e diferentes estruturas ou modelos conceituais usados nas publicações de Enfermagem, postula uma Teoria Geral do Cuidado, sistematizando o conceito de processo de cuidado para a formulação do conceito estratégico e operacional de processo saúde-doençacuidado cujos fundamentos históricos encontra na própria Enfermagem: PSDC é um conceito histórico, adstraído das vivências e experiências individuocoletivas de cuidado (e de não cuidado) com o corpo e com os ambientes, espaços e contextos da vida humana, incluindo todos os demais ecossistemas vivos; por ser histórico possui indissociáveis as dimensões biológicas, psicológicas, sociais, antropológicas (culturais, étnicas-pluriétnicas-interétnicas, de gênero, políticas, econômicas...), gerenciais, epistêmicas (no sentido dos conhecimentos disciplinares e pluridisciplinares profissionais ou não produzidos sobre ele, incluindo arquitetura, engenharia, ecologia). 
Quadro 1 - Distribuição dos artigos por sintagmas, ano e revista de publicação

\begin{tabular}{|c|c|c|c|}
\hline Sintagmas & Ano & Número & Revista \\
\hline processo da morte e do morrer & 1992 & 1 & Texto Contexto Enfermagem \\
\hline processo de ser saudável/adoecer/curar & 1992 & 1 & Texto Contexto Enfermagem \\
\hline processo de viver/ser saudável/adoecer e curar & 1993 & 1 & Texto Contexto Enfermagem \\
\hline processo saúde-doença-cuidado & 2000 & 1 & Latinoamericana Enfermagem \\
\hline processo saúde-doença-cuidado & 2003 & 1 & Brasileira de Enfermagem \\
\hline processo saúde-doença-cuidado & 2005 & 1 & Latinoamericana Enfermagem \\
\hline processo saúde-doença-cuidar & 2005 & 1 & Ciência e Saúde Coletiva \\
\hline processo saúde-doença-cuidado & 2006 & 2 & Bras.de Enferm/EscEnfUSP \\
\hline processo saúde-doença-cuidado & 2006 & 1 & Interface Saúde Coletiva \\
\hline processo (s)saúde/enfermidade/atenção & 2006 & 1 & Salud Colectiva, Buenos Aires \\
\hline processo saúde-doença-cuidado & 2007 & 2 & Latinoam Enferm/Texto Contexto Enferm \\
\hline processo saúde-padecimento-enfermidade/atenção & 2007 & 1 & Salud Pública de México \\
\hline processo saúde-enfermidade-atenção & 2007 & 2 & Salud Colectiva, Buenos Aires \\
\hline $\left.\begin{array}{l}\text { processo (s) de saúde/doença/cuidado } \\
\text { processo saúde/doença/cuidado }\end{array}\right\}$ & 2007 & 1 & Ciência e Saúde Coletiva \\
\hline $\begin{array}{l}\text { processo saúde-doença-cuidado } \\
\text { processo sofrimento-adoecimento-cuidado }\end{array}$ & 2007 & 1 & Psicologia em Estudo \\
\hline processos de saúde/enfermidade/atenção & 2008 & 1 & Salud Colectiva, Buenos Aires \\
\hline processo saúde-doença-cuidado & 2009 & 1 & Saúde e Sociedade \\
\hline processo de saúde-doença-cuidado & 2010 & 1 & Texto Contexto Enfermagem \\
\hline processo saúde-doença-cuidado & 2010 & 1 & Enfermagem UFPE \\
\hline processos de saúde-doença-atenção & 2010 & 1 & Cadernos de Saúde Pública \\
\hline processo saúde-doença-cuidado & 2011 & 1 & Nutrição \\
\hline Total & & 24 & \\
\hline
\end{tabular}

Fonte: o autor

Quadro 2 - Distribuição de sintagmas por ano de publicação e autor de capítulo de livros

\begin{tabular}{|c|c|c|}
\hline sintagmas & $\begin{array}{l}\text { Ano de } \\
\text { publicação }\end{array}$ & Autor do capítulo de livro \\
\hline processo saúde/enfermidade/atenção & 1998 & Eduardo L. Menéndez \\
\hline processo saúde-doença e cuidado & 1999 & $\begin{array}{l}\text { Maria Cecília Puntel de Almeida, Pedro Fredemir Palha, } \\
\text { Maria Márcia Leite Nogueira Domingos, Silvana Martins } \\
\text { Mishima, Tereza Cristina Scatena Villa e Maria das Dores } \\
\text { do Vale Oba }\end{array}$ \\
\hline processo saúde-enfermidade-cuidado e $Z$ & - & - \\
\hline processo saúde-doença-cuidado & $2003\}$ & Paulo Marchiori Buss \\
\hline processo de saúde-doença e sofrimento & 2004 & Alda Lacerda e Victor Vincent Valla \\
\hline processo de ser saudável-adoecer-curar-se & 2004 & Ricardo Burg Ceccim \\
\hline processos saúde/enfermidade/cuidados & 2005 & Luíza Garnelo e Esther Jean Langdon \\
\hline Total & 6 & \\
\hline
\end{tabular}

Fonte: o autor

Quadro 3 - Distribuição de sintagmas por ano de publicação e autor (es) de livros

\begin{tabular}{lll}
\hline Sintagmas & $\begin{array}{l}\text { Ano de } \\
\text { publicação }\end{array}$ & Autor de livro \\
\hline processo de ser e viver saudável & 1997 & Alcione Leite da Silva \\
processo saúde-doença-cuidado & 2010 & Carlos Roberto Fernandes \\
\hline Total & $\mathbf{2}$ & \\
\hline
\end{tabular}

Fonte: o autor

Quadro 4 - Distribuição de sintagmas em Anais por ano de publicação e autor(es)

\begin{tabular}{lcl}
\hline Sintagmas & $\begin{array}{c}\text { Ano dos } \\
\text { Anais }\end{array}$ & Autor do trabalho \\
\hline processo saúde-doença-cuidado & 2009 & $\begin{array}{l}\text { Carlos Roberto Fernandes e } \\
\text { Robson Weligton de Souza }\end{array}$ \\
\hline Total & $\mathbf{1}$ & \\
\hline
\end{tabular}

Fonte: o autor 


\section{Bibliografia}

1.Almeida MCP, Palha PF, Domingos MMLN, Mishima SM, Villa TCS, Oba MDV. A Classificação Internacional da prática de Enfermagem em Saúde Coletiva no Brasil CIPESC/ICN/ABEN e o processo de trabalho. In: Chianca TCM, Antunes MJM (orgs.). A Classificação Internacional das Práticas de Enfermagem em Saúde Coletiva - CIPESC. 1. ed. Brasília: Associação Brasileira de Enfermagem; 1999. p.46-56

2.Alves VS, Nunes MO. Educação em Saúde na atenção médica ao paciente com hipertensão arterial no Programa Saúde da Família. Interface - Comunic, Saúde, Educ, 2006; 9(18):131-47

3.Bezerra STF, Silva LF. Cuidado de Enfermagem fundamentado no modelo conceitual e na teoria de alcance de metas. Rev enferrm UFPE [On line]. 2010 jul-set; 4(3):1550-6. Disponivel em: http://www.revista.ufpe.br/revistaenfermagem/index.php/revista/article/viewFile/992/pdf_155

4.Brant LC, Gomes CM. Dispositivos de transformação do sofrimento em adoecimento numa empresa. Psicologia em Estudo. 2007 set-dez; 12(3):465-473

5.Buss PM. Uma introdução ao conceito de Promoção da saúde. In: Czeresnia, D, Freitas CM (orgs). Promoção da saúde: conceitos, reflexões, tendências. 1. ed. Rio de Janeiro: Fiocruz; 2003. p. $15-38$

6.Canto JO. Géneros y generaciones: conducta reproductiva de los Mayas de Yucatán, México. Salud Colectiva Buenos Aires. 2006; 2(1):75-89

7.Ceccim RB. Equipe de Saúde: a perspectiva entre-disciplinar na produção dos atos terapêuticos. In: Pinheiro R, Mattos RA (orgs.). Cuidado: as fronteiras da integralidade. 1. ed. Rio de Janeiro: Hucitec/Abrasco; 2004. p.259-278

8.Demétrio F, Paiva JB, Fróes AAG, Freitas MCS, Santos LAS. A Nutrição Clínica Ampliada e a humanização da relação nutricionista-paciente: contribuições para reflexão. Rev Nutr. 2011; 24(5):743-763

9.Diehl EE, Grassi F. Uso de medicamentos em uma aldeia Guarani do litoral de Santa Catarina, Brasil. Cad. Saúde Pública. 2010 ago; 26(8):1549-1560

10.Dilthey W. Das Wesen der Philosophie. 1. ed. alemã. In: P. Hinneburg (editor). Die Kultur der Gegenwart. Berlim: B.G.Teubner; 1907. p.1-72

11.Dilthey W. Fundamientos de un Sistema de Pedagogía. Tradução de Lorezo Luzuriaga. 3. ed. en español. Buenos Aires: Losada; 1949

12.Dilthey W. Crítica de la razón histórica. Tradução e prólogo de Carlos Moya Espí. 1. ed. espanhol. Barcelona: Península; 1986

13.Dilthey W. La esencia de la filosofia. Tradução de Elsa Tabernig. 1. ed. espanhol Coleção de Obras Maestras del Pensamiento. Buenos Aires: Losada; 2003

14.Ditterich RG, Cabardo MCL, Moysés SJ. As Ferramentas de trabalho com famílias utilizadas pelas equipes de Saúde da Família de Curitiba, PR. Saúde Soc. 2009 18(3):515-24

15.Fernandes CR, Souza RW. Abordagem clínica da violência moral na lógica do processo saúdedoença-cuidado. ln: Anais do 15o. Seminário Nacional de Pesquisa em Enfermagem; 2009 jun 811; Rio de Janeiro (RJ), Brasil. Rio de Janeiro: ABEn; 2009. p. 1791-3.

16.Fernandes CR. Fundamentos do processo saúde-doença-cuidado. 1. ed. Rio de Janeiro: Águia Dourada; 2010

17.Gadamer, HG. Verdade e método: traços fundamentais de uma Hermenêutica Filosófica. Tradução de Flávio Paulo Meurer. 3. ed. Petrópolis: Vozes; 1999 
18.Egry EY, Sena RR. O Desenvolvimento do conhecimento na enfermagem. In: SENA, Roseni R. de (Editora). Educación de enfermería en América Latina. 1. ed. Colômbia: Real; 2000. p.13-39

19.Fernandes CR. Violência moral na Enfermagem. 1. ed. Goiânia: AB; 2007

20.Garnelo L, Langdon J. A Antropologia e a reformulação das práticas sanitárias na atenção básica à saúde. In: Minayo MCS, Coimbra Júnior CEA (orgs.). Criticas e atuantes: Ciências Sociais e Humanas em Saúde na América Latina. 1. ed. Rio de Janeiro: Fiocruz; 2005. p. 135-156

21.Gomes R, Schraiber LB, Couto MT. O Homem como foco da Saúde Pública. Rev Ciência \& Saúde Coletiva. 2005 jan-mar; 10(1):4-5.

2.Lacerda A, Valla VV. As Práticas terapêuticas de cuidado integral à saúde como proposta para aliviar o sofrimento. In: Pinheiro R, Mattos RA (orgs.). Cuidado: as fronteiras da integralidade. 1. ed. Rio de Janeiro: Hucitec/Abrasco. 2004; p.91-102

23.Leopardi MT. Para além do trabalho alienado: a utopia de ser saudável. Texto Contexto Enferm. 1992 jul-dez; 1(2):76-88

24.Leopardi MT. Por quê Filosofia em Enfermagem?. Texto Contexto Enferm. 1993 jan-jun; 2(1):5-12.

25.Lopes MSV, Saraiva KRO, Fernandes AFC, Ximenes LB. Análise do conceito de promoção da saúde. Texto Contexto Enferm. 2010 jul-set; 19(3): 461-8

26.Machado LRC, Car MR. Dialética do modo de vida de portadores de hipertensão arterial: o objetivo e subjetivo. Rev Esc Enferm USP. 2006; 41(4):573-80

27.Mazzeo V. La situación de la salud-enfermedad-atención de la primera infância em la Ciudade de Buenos Aires entre 1990 y 2002. Salud Colectiva Buenos Aires. 2007; 3(3): 285-300

28.Menéndez EL, Di Pardo RB. La representación social negativa de los procesos de salud/enfermedad/atención em la prensa escrita. Salud Colectiva Buenos Aires. 2008, jan-abr, 4(1):9-30

29.Menéndez EL. Antropologia Médica e Epidemiologia. Processo de convergência ou processo de medicalização? Alves PC, Rabelo MC (orgs.). Antropologia da Saúde: traçando identidade e explorando fronteiras. 1. ed. Rio de Janeiro: Fiocruz; 1998

30.Moraes IHS, Gómez MNG. Informação e Informática em saúde: caleidoscópio contemporâneo da saúde. Ciência \& Saúde Coletiva. 2007; 12(3):553-565

31.Moreno-Altamirano L. Reflexões sobre el trayecto salud-padecimiento-enfermedad-atención: uma mirada socioantropológica. Salud Pública de México. 2007 jan-fev; 49(1):63-70

32.Pinho LB, Santos SMA. O Processo saúde-doença-cuidado e a lógica do trabalho do enfermeiro na UTI. Rev Latino-am Enferm. [Online]. 2007 mar-abr; 15(2). Disponível em: www.eerp.usp.br/rlae

33.Reis AL, Xavier IM. Mulher e aids: rompendo o silêncio de adesão. Rev Bras Enferm. 2003; 56(1): 28-34

34.Rocha SMM, Almeida MCP. O Processo de trabalho da Enfermagem em Saúde Coletiva e a interdisciplinaridade. Rev. latinoam. Enferm. 2000 dez; 8(6): 96-101

35.Rosa AS, Cavicchioli MGS, Brêtas ACP. O Processo Saúde-Doença-Cuidado e a população em situação de rua. Rev Latino-am Enfermagem. [Online]. 2005 jul-ago; 13(4):576-82. Disponível em: www.eerp.usp.br/rlae

36.Rosa AS, Cavicchioli MGS, Brêtas ACP. O Cuidado em situação de rua: revendo o significado do processo saúde-doença. Rev Bras Enferm. 2006 mai-jun; 59(3):331-6 
37.Sacchi M, Hausberger M, Pereyra A. Percepción del proceso salud-enfermedad-atención y aspectos que influyen en la baja utilización del Sistema de Salud, em famílias pobres de la ciudad de Salta. Salud Colectiva Buenos Aires. 2007; 3(3):271-283

38.Silva AL. Cuidado transdimensional: um paradigma emergente. 1.ed. Pelotas: UniversitáriaUFPel; 1997

39.Silva AL, Borenstein MS. Ser e viver saudável no mundo: buscando novos caminhos no cuidar pesquisando com o ser-doente. Texto Contexto Enferm. 1992 jul-dez; 1(2):56-69

40.Toledo MM, Rodrigues SC, Chiesa AM. Educação em Saúde no enfrentamento da hipertensão arterial: uma nova ótica para um velho problema. Texto Contexto Enferm 2007 abr-jun; 16(2):2338 